\title{
The history of the use of intrathecal prostigmine to achieve fertility in men with spinal cord injuries
}

\author{
J. R. Silver ${ }^{1}$ - M.-F. Weiner ${ }^{2}$
}

Received: 29 October 2018 / Revised: 4 February 2019 / Accepted: 25 March 2019

(c) International Spinal Cord Society 2019

\section{Introduction}

For many years, there had been a widespread and inaccurate belief that men who have suffered a spinal cord injury (SCI) were permanently and completely impotent and sterile. Ludwig Guttmann introduced the prostigmine test whereby it was injected intrathecally to produce erections and emissions and carried out systematic research to achieve fertility among male patients with an SCI. Despite his undoubted authority in the field, the test received widespread opposition at the time and eventually, because of the risks involved and the death of a patient, it was abandoned. Nevertheless, it served as a stimulus for the development of the modern approach towards sexual function in men with a spinal injury. The history of these controversies is of relevance to professionals treating patients with spinal injuries today.

\section{Historical background}

In 1936, M. Kremer, H.E.S. Pearson and Wright carried out research in Samson Wrights' Department of Physiology at the Middlesex Hospital Medical School where they studied the effect of intrathecal injections of $1-1.5 \mathrm{mg}$ of prostigmine in 8 patients [1]. Prostigmine (generic name neostigmine) is a cholinesterase inhibitor. It is a parasympathomimetic agent that acts as a reversible acetylcholinesterase inhibitor. It does not cross the blood-brain barrier.

\footnotetext{
M.-F. Weiner

jrussellsilver@btconnect.com

1 National Spinal Injuries Centre, Stoke Mandeville Hospital, Aylesbury, UK

2 Oxford Brookes University, Oxford, UK
}

They showed that injecting $1 \mathrm{mg}$ of prostigmine into the cerebrospinal fluid (CSF) of patients with hemiplegia decreased or abolished tendon reflexes and muscle tone in the legs and occasionally in the arms without a change in sensation. Kremer continued this research and studied 37 patients, injecting different dosages of prostigmine in the lumbar theca on 73 occasions [2]. In all cases, this produced a depression of muscle tone and reflexes by direct action on the spinal cord. There were severe side effects: nausea, vomiting, drowsiness and paralysis of the bladder necessitating catheterisation and some patients had to be revived with Coramine. Coramine is a stimulant that mainly affects the respiratory cycle.

Kremer served in the Second World War as a consultant neurologist in the Army. After the war, there were no positions for army neurologists and he was appointed temporarily as a neurologist at Stoke Mandeville Hospital in the adjacent ward to where Ludwig Guttmann was working. Ludwig Guttmann, who was in charge of the spinal unit, became aware of the work carried out by Kremer which showed that prostigmine reduced muscle tone and reflexes. As he was looking for a means of reducing spasticity in patients with an SCI, he thought he would experiment with prostigmine. This is when fortuitously he discovered that prostigmine induced erections and emissions in patients with traumatic paraplegia and complete transverse lesions of the spinal cord.

The intrathecal injection of prostigmine has a direct action on the central nervous system. It decreases or abolishes the tendon reflexes and muscle tone. This is followed by vomiting, drowsiness and an inability to pass urine. It depresses spinal reflexes and decreases the strength of the voluntary movements due to direct action on the spinal cord. This effect is in striking contrast to the stimulating effect of this drug on the muscular system following intramuscular injections. Furthermore, intrathecal injection of prostigmine has a stimulating effect on the reproductive function in contrast to its depressing effect on the skeletal muscles and the bladder as described by Kremer in 1942 [2]. 
The Quechenstedt test was carried out to see whether there was a subarachnoid block and to establish the dosage of prostigmine. For the test, the jugular veins on either side of the canal are compressed alternately. The pressure of the spinal fluid is measured by a manometer connected to a lumbar puncture needle or catheter. Normally, occlusion of the veins of the neck causes an immediate rise in spinal fluid pressure. If the vertebral canal is blocked, no rise occurs. In the absence of a block or if there was a partial block, $0.3 \mathrm{mg}$ of prostigmine was injected after aspirating CSF into the syringe to mix with the prostigmine. In patients with high thoracic and cervical injuries, treatment was begun with $0.25 \mathrm{mg}$ because of the associated rise in blood pressure (BP) in such patients during ejaculations, 'which may have resulted in severe autonomic hyperreflexia' [3]. Autonomic dysreflexia (AD) is experienced as a result of the forceful contraction of the bladder and other internal organs [4]. Up to $1.5 \mathrm{mg}$ of prostigmine was given in one exceptional case of a conus-cauda equina lesion. Subsequently, reflexes and muscle tone were examined in the lower limbs every $1 / 2-1 \mathrm{~h}$. In addition, pulse and BP were measured.

Five studies (see Table 1) were identified on the use of prostigmine in patients with spinal injuries (in no case was eserine, a reversible cholinesterase inhibitor, used). In all cases, the semen was examined and the sperm count was reduced. There were two large systematic studies, one by Guttmann and Walsh and the other by Piera et al. [5, 6]. The largest series was by Guttmann and Walsh who assembled 134 cases aggregating their previous studies including patients with cord transections above T6 who were at risk of developing AD. Piera and Grossiord described 100 cases from a series of papers but none with transections of the cord above T11. They did not observe any patients with $\mathrm{AD}$. Chapelle et al. described in detail one case from that study [7]. Two additional studies by Spira and Rossier described isolated cases but none with transections of the cord above $\mathrm{T} 7[8,9]$.

\section{Discussion}

\section{Complications and patient selection}

Kremer did not use prostigmine as a fertility test; he was investigating the physiology of nerve transmission within the spinal cord. He did observe the complication of retention of urine and how some patients lost consciousness and had to be revived with Coramine. He did not observe any episodes of AD. None of the cases he studied were patients with traumatic spinal injuries, the majority suffered from hemiplegia, with the exception of two patients who had a spinal block due to carcinomatosis of the spinal column.

Guttmann and Walsh were aware of the complications in patients with transections of the cord above T6 but still carried out the tests. They studied 10 patients with cervical injuries and another 30 patients with transections of the cord above T6, a total of 40 'at risk' patients in their series of 134 cases. They described severe side effects with BP rising up to 230 over $150 \mathrm{~mm} \mathrm{Hg}$ and they describe one death:

'We lost one tetraplegic with a complete C6/7 lesion.

He died after an epileptic fit and cerebral haemor-

rhage, severe intra cerebral bleed' [5].

At Stoke Mandeville under Guttmann, the prostigmine test was used systematically from 1947 to assess the potentialities of sexual function. They also observed that intrathecal injections of prostigmine caused retention of urine for several hours. In France, Piera and Chapelle were aware of complications such as $\mathrm{AD}$ as a result of prostigmine injections and restricted their studies to patients with transections of the cord below T10. Spira recorded no complications. Guttmann and Walsh recognised that AD occurred. Rossier investigated this phenomenon in detail (see Figs. 1 and 2). He demonstrated that AD was a direct

Table 1 Prostigmine test studies

\begin{tabular}{|c|c|c|c|c|c|}
\hline Names & $\begin{array}{l}\text { Number of patients } \\
\text { and level of the } \\
\text { transections }\end{array}$ & $\begin{array}{l}\text { Number of } \\
\text { prostigmine tests }\end{array}$ & No. of successful pregnancies & Complications & $\begin{array}{l}\text { Purpose of test: } \\
\mathrm{D}=\text { diagnosis, } \\
\mathrm{T}=\text { treatment }\end{array}$ \\
\hline $\begin{array}{l}\text { Piera JB/Grossiord } \\
\text { France, Garches [6] }\end{array}$ & $\begin{array}{l}100 \\
\mathrm{~T} 10-\mathrm{S} 4\end{array}$ & 74 & $\begin{array}{l}2 \text { (not clear if due to } \\
\text { prostigmine test) }\end{array}$ & No mention & $\mathrm{D} / \mathrm{T}$ \\
\hline $\begin{array}{l}\text { Chapelle et al., } \\
\text { France, Garches [7] }\end{array}$ & $\begin{array}{l}1 \\
\mathrm{~T} 7-\mathrm{T} 8\end{array}$ & 2 & $\begin{array}{l}1 \text { but paternity questionable as } \\
\text { offspring a different blood } \\
\text { group to the parents }\end{array}$ & No mention & $\mathrm{T}$ \\
\hline $\begin{array}{l}\text { Guttmann and } \\
\text { Walsh } \\
\text { [5], UK SMH }\end{array}$ & $\begin{array}{l}134 \\
10 \text { cervical } \\
30 \text { up to T6 }\end{array}$ & $\begin{array}{l}134 \text { (some } \\
\text { multiple) }\end{array}$ & 2 but aborted & $\begin{array}{l}\text { Yes autonomic } \\
\text { dysreflexia one death }\end{array}$ & $\mathrm{D} / \mathrm{T}$ \\
\hline Spira [8], Israel & $\begin{array}{l}1 \\
\mathrm{~T} 8\end{array}$ & 6 & $\begin{array}{l}\text { Yes (+paternity test } \\
\text { confirmation) }\end{array}$ & No mention & $2 \mathrm{D} / 4 \mathrm{~T}$ \\
\hline $\begin{array}{l}\text { Rossier et al. [9] } \\
\text { Switzerland }\end{array}$ & $\begin{array}{l}1 \\
\mathrm{C} 7-\mathrm{C} 8\end{array}$ & 1 & no & Severe dysreflexia & $\mathrm{D}$ \\
\hline
\end{tabular}


Sch. V. $\sigma^{\prime \prime} 22.5 .1939$

Complete tetraplegia $\mathrm{C7}-\mathrm{C} 8$ bilat.

Fract. disl. C6-C7 (car accident: 24.11.1961).

Prostigmine test on 27.8.1969.

Continuous recording of blood pressure by intrafemoral catheter with simultaneous electrocardiogram.

Recording made 62 minutes after the intrathecal injection of $0,25 \mathrm{mg}$ of prostigmine.

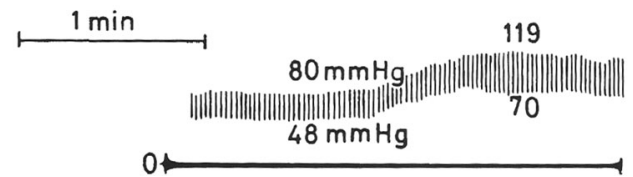

Fig. 1 Intra arterial pressure monitoring showing one out of the four short-lasting increases of blood pressure, which occurred after the first intrathecal injection of neostigmine. Rossier et al. [9]. Reproduced with permission from Nature Publishing

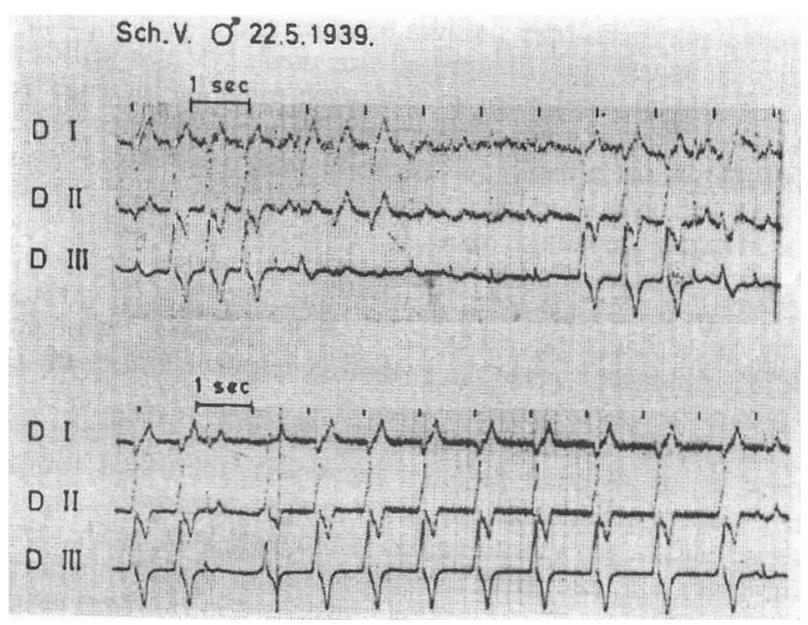

Fig. 2 Outbursts of heterotopic complexes during the first ejaculation following the second intrathecal injection of neostigmine in the same test. Rossier et al. [9]. Reproduced with permission from Nature Publishing

consequence of the injection of prostigmine and was to be expected in every case. He described how every ejaculation following an injection of neostigmine (a derivative of prostigmine) in patients with a lesion of the spinal cord above $\mathrm{T} 6$ resulted in severe symptoms of $\mathrm{AD}$ including raised BP and important modifications of cardiac activity, increasing the risk of strokes. He also states that the rise in BP was not due to a change in the cardiac output but was caused by a vasoconstriction in the paralysed blood vessels below the cervical outflow [9]. He observed a urinary increase in the production of adrenaline and noradrenaline. The bradycardia was due to an overproduction of noradrenaline. This was mediated by a central regulatory mechanism via receptors from the aortic arch and carotid sinus. His findings remain pertinent today and have been confirmed by subsequent investigators [10].

$\mathrm{He}$ concluded that there was a direct relationship between sexual activity and AD in patients with high spinal cord lesions. The AD experienced as a result of the prostigmine test was much more severe and devastating than that resulting from bladder distension. With bladder distension, the $\mathrm{AD}$ disappeared within moments of emptying the bladder, while after a prostigmine injection, the $\mathrm{AD}$ continued for up to $4 \mathrm{~h}$, because the prostigmine was still in the patient's bloodstream.

\section{The prostigmine test as a fertility treatment}

Because of the dangers, the test was of questionable benefit to induce erections and ejaculations to allow conception to occur through artificial insemination. While in some cases it allowed patients with an SCI to have erections and emissions, in Guttmann and Walsh's experiments, the erections and ejaculations occurred, but in the other studies when they failed to produce an ejaculation, they masturbated to produce an ejaculation (see [6-9]). With regard to achieving fertility, the statistics were disappointing. Overall, the studies resulted in five pregnancies, three live births but only one demonstrably attributed to prostigmine.

Despite Guttmann's enthusiasm and authority in the field and his advocacy of this form of treatment, the prostigmine test had little uptake. It is quite clear from the outset that the development of severe $\mathrm{AD}$ was not a complication but an integral and inevitable consequence of the injection of prostigmine and the resulting uncontrolled rise in BP could be fatal as recorded by Guttmann and Walsh. It was acknowledged that rises in BP as a result of bladder distension had resulted in numerous deaths among patients with SCIs [11]. They stressed the necessity of recording the $\mathrm{BP}$ and making provision to have antihypertensives available whenever the test was carried out.

It was clearly inappropriate to use this therapy to achieve intercourse since the patient could not perform a lumbar puncture on himself. Additionally, the success rate following the collection of sperm for artificial insemination was so poor as not to justify the treatment. Apart from a few cases in the French units, the prostigmine test was not adopted outside Stoke Mandeville Hospital, and at the time, the procedure was widely criticised.

\section{Controversy}

Despite Guttmann's eminence and authority in the field, this procedure did not receive either universal acceptance or acclaim.

H. Talbot, the doyen among American spinal injury consultants, who was president of the International Spinal 
Cord society (ISCoS) from 1970 to 1973 , concluded that the test was difficult to justify on fertility grounds.

Patients' lives are endangered. Although we appreciate the desire to have children we must remember and remind ourselves that there is a reasonably good substitute. The insistence on natural parenthood is not worth certainly not in my estimation the risk of procedures that can be dangerous or adulterous [12].

M. Maury, a tetraplegic himself, was eminent consultant in charge of a spinal unit in Fontainebleau in France and a pioneer on rehabilitation. He said the prostigmine test should not be done.

After having made rare intrathecal injections of prostigmine we have asked ourselves if this technique, which constitutes an important factor in the fertilising possibilities for the paraplegic, deserves to be continued. In fact, the chances of fertility by one insemination are very weak. There are a lot of factors which could influence the quality and the quantity of the sperm and moreover, the prostigmine test is not without danger [12].

At Stoke Mandeville Hospital, the prostigmine test was abandoned after Guttmann retired. Walsh never published on the subject after he discovered that he could produce an ejaculation by inserting an electrical probe in the patients' rectum. Burr, the biochemist to the spinal unit at Stoke Mandeville Hospital, said that they had abandoned the prostigmine test because they were not allowed to store sperm samples [Burr and Silver, personal communication].

It is significant that prostigmine tests were never carried out in the United States. Neither E. Bors, consultant in charge of the spinal unit in Long Beach California nor D. Yashon, Professor of Neurosurgery at the Ohio State University Hospital mentioned the procedure and the prostigmine test does not feature in Bors' 1963 textbook on urodynamics [13, 14]. Silver and his colleagues at Stoke Mandeville Hospital never adopted the prostigmine test.

\section{The consequences}

Despite the widespread rejection of the test outside Stoke Mandeville Hospital, it did open up the subject of sexual function and direct attention on the possibility of patients with a spinal injury achieving intercourse, and in the United Kingdom, it contributed to making sexual function in paralysed patients not a forbidden subject but one that could be discussed and treated. This was a subject which until then had been neglected.

\section{Prostigmine and its influence on present day practice}

Successful sexual relationships are of paramount importance and concern to patients. The medical profession's reluctance to talk about sexual function is partly attributable to a lack of training of the doctors. This leads to poor advice from the medical profession despite the importance of sexual function to people with a disability. Unfortunately, the onset of chronic illness or physical disability was assumed to eliminate sex drive and, for many years, this governed the behaviour of rehabilitation and healthcare professionals. As a result, patients suffered from low selfesteem and guilt and were ostracised from society, barred from marriage and in some cases institutionalised. It was not unusual for a person with a spinal injury to be told that he/she would never marry or have a family and that it would be better to put these issues out of their mind [15]. While discussing sexual function was a taboo subject, in the 1960s, with the sexual revolution, attitudes changed and it was not unusual for patients to form sexual relationships with staff.

German medicine, in contrast, was light years ahead of Britain. German doctors were interested in sexual function. German refugees came to Samson Wright's laboratory and said they wanted to do research on sexual function (electroencephalogram, pulse, etc... during intercourse) and described experiments on humans. When Samson Wright explained that this was not ethically allowed in the United Kingdom, they went to the United States to carry out their research [Kremer and Silver, personal communication]. In the United States, Mary Tremblay described how War Veterans were pioneers in the areas of marriage, family life and adoption. Following the war, veterans with an SCI were encouraged to marry, something not usually accepted in this period [16].

\section{Conclusion}

Evidence against the prostigmine test was overwhelming (this procedure would not be approved today). At the time, paradoxically, licences were required to perform experiments on animals but not on humans and there were no ethical committees. The prostigmine test revealed that sexual function in men with a spinal injury was possible. This discovery together with changes in society's attitude towards sexuality led to further research into a subject that until then had been neglected and avoided by the medical profession.

Acknowledgements We wish to thank the late Professor Mike Oliver for his help and suggestions. 


\section{Compliance with ethical standards}

Conflict of interest The authors declare that they have no conflict of interest.

Publisher's note: Springer Nature remains neutral with regard to jurisdictional claims in published maps and institutional affiliations.

\section{References}

1. Kremer M, Pearson HES, Wright S. Action of prostigmine on spinal cord in man. Proc. Physiol. Soc. 1936;21-3.

2. Kremer M. Action of intrathecally injected prostigmine, acetylcholine and eserine on the central nervous system in man. Quart J Exp Physiol. 1942;31:337-57.

3. Guttmann L, Whitteridge D. Effects of bladder distension on autonomic mechanisms after spinal cord injuries. Brain. 1947;70:361-404.

4. Guttmann L. Spinal cord injuries comprehensive management and research. Oxford: Blackwell Scientific Publications; 1973. p. 460-1.

5. Guttmann L, Walsh JJ. Prostigmine assessment test of fertility in spinal man. Paraplegia. 1971;9:39-51.

6. Piera JB. The establishment of a prognosis for genito-sexual function in the paraplegic and tetraplegic male. Paraplegia. 1973;10:271-8.
7. Chapelle PA, Jondet M, Durand J, Grossiord A. Pregnancy of the wife of a complete paraplegic by homologous insemination after an intrathecal injection of neostigmine. Paraplegia. 1976;14:173-7.

8. Spira R. Artificial insemination after intrathecal injection of neostigmine in a paraplegic. Lancet. 1956;270:670-1.

9. Rossier AB, Ziegler WH, Duchosal PW, Meylan J. Sexual function and dysreflexia. Paraplegia. 1971;9:51-9.

10. Weaver LC, Fleming JC, Mathias CJ, Krassioukov AV. Disordered cardiovascular control after spinal cord injury. Handb Clin Neurol. 2012;109:213-33.

11. Krassioukov, et al. Autonomic dysreflexia. In: Chhabra HS, editor. ISCoS textbook of comprehensive management of spinal cord injuries. New Delhi: Wolters Kluwer; 2015. p. 814.

12. Deyoe FS. Marriage and family patterns with long term spinal cord injury. Spinal Cord. 1972;10:219-24.

13. Harris P. Proceedings of the symposium on spinal injuries. Edinburgh: Royal College of Surgeons; 1963. p. 105.

14. Bors E. Sexual function in patients with spinal cord injury. Edinburgh: Proceedings of the Symposium of Royal College of Surgeons; 1963.

15. Trieschmann RB. Spinal cord injuries: psychological, social and vocational adjustment. Oxford: Pergamon Press Ltd; 1988. p. $127-9$.

16. Tremblay Mary, Gerber DA. Disabled veterans in history. Michigan: Michigan Press; 2000. p. 322-46. 